University of Nebraska - Lincoln

DigitalCommons@University of Nebraska - Lincoln

Other Publications in Zoonotics and Wildlife

Disease

Wildlife Disease and Zoonotics

$4-27-2000$

\title{
Ceftriaxone-Resistant Salmonella Infection Acquired by a Child from Cattle
}

\author{
Paul D. Fey \\ University of Nebraska Medical Center, Omaha \\ Thomas J. Safranek \\ Nebraska Department of Health and Human Services, tom.safranek@nebraska.gov \\ Mark E. Rupp \\ University of Nebraska Medical Center, Omaha \\ Eileen F. Dunne \\ Centers for Disease Control and Prevention, Atlanta \\ Efrain Ribot \\ Centers for Disease Control and Prevention, Atlanta \\ See next page for additional authors
}

Follow this and additional works at: https://digitalcommons.unl.edu/zoonoticspub

Part of the Veterinary Infectious Diseases Commons

Fey, Paul D.; Safranek, Thomas J.; Rupp, Mark E.; Dunne, Eileen F.; Ribot, Efrain; Iwen, Peter C.; Bradford, Patricia A.; Angulo, Frederick J.; and Hinrichs, Steven H., "Ceftriaxone-Resistant Salmonella Infection Acquired by a Child from Cattle" (2000). Other Publications in Zoonotics and Wildlife Disease. 44. https://digitalcommons.unl.edu/zoonoticspub/44

This Article is brought to you for free and open access by the Wildlife Disease and Zoonotics at DigitalCommons@University of Nebraska - Lincoln. It has been accepted for inclusion in Other Publications in Zoonotics and Wildlife Disease by an authorized administrator of DigitalCommons@University of Nebraska - Lincoln. 


\section{Authors}

Paul D. Fey, Thomas J. Safranek, Mark E. Rupp, Eileen F. Dunne, Efrain Ribot, Peter C. Iwen, Patricia A. Bradford, Frederick J. Angulo, and Steven H. Hinrichs 


\title{
CEFTRIAXONE-RESISTANT SALMONELLA INFECTION ACQUIRED BY A CHILD FROM CATTLE
}

\author{
Paul D. Fey, Ph.D., Thomas J. Safranek, M.D., Mark E. Rupp, M.D., Eileen F. Dunne, M.D., M.P.H., \\ Efrain Ribot, Ph.D., Peter C. Iwen, M.S., Patricia A. Bradford, Ph.D., Frederick J. Angulo, D.V.M., Ph.D., \\ AND SteVen H. HINRICHS, M.D.
}

\begin{abstract}
Background The emergence of resistance to antimicrobial agents within the salmonellae is a worldwide problem that has been associated with the use of antibiotics in livestock. Resistance to ceftriaxone and the fluoroquinolones, which are used to treat invasive salmonella infections, is rare in the United States. We analyzed the molecular characteristics of a ceftriaxone-resistant strain of Salmonella enterica serotype typhimurium isolated from a 12-year-old boy with fever, abdominal pain, and diarrhea.
\end{abstract}

Methods We used pulsed-field gel electrophoresis and analysis of plasmids and $\beta$-lactamases to compare the ceftriaxone-resistant $S$. enterica serotype typhimurium from the child with four isolates of this strain obtained from cattle during a local outbreak of salmonellosis.

Results The ceftriaxone-resistant isolate from the child was indistinguishable from one of the isolates from cattle, which was also resistant to ceftriaxone. Both ceftriaxone-resistant isolates were resistant to 13 antimicrobial agents; all but one of the resistance determinants were on a conjugative plasmid of 160 $\mathrm{kb}$ that encoded the functional group $1 \beta$-lactamase CMY-2. Both ceftriaxone-resistant isolates were closely related to the three other salmonella isolates obtained from cattle, all of which were susceptible to ceftriaxone.

Conclusions This study provides additional evidence that antibiotic-resistant strains of salmonella in the United States evolve primarily in livestock. Resistance to ceftriaxone, the drug of choice for invasive salmonella disease, is a public health concern, especially with respect to children, since fluoroquinolones, which can also be used to treat this disease, are not approved for use in children. (N Engl J Med 2000;342:1242-9.)

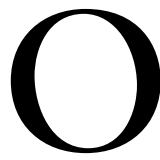
F the estimated 1.4 million salmonella infections that occur each year in the United States, most are in children and the elderly and approximately 600 are fatal. ${ }^{1}$ Septicemia complicates at least 7 percent of the 40,000 culture-confirmed infections that are reported each year. ${ }^{1,2}$ Although antibiotics are not essential for the treatment of most cases of salmonellosis, they can be lifesaving in persons with invasive disease. Expandedspectrum cephalosporins (e.g., ceftriaxone) are commonly used to treat salmonella infections in children because of their pharmacodynamic properties and the very low prevalence of resistance to these agents. Since 1991, salmonella species that are resistant to expanded-spectrum cephalosporins have been reported in several countries, including Argentina, Turkey, Algeria, Saudi Arabia, Greece, Tunisia, and France..$^{3-12}$ In these isolates, a variety of $\beta$-lactamases from functional groups 1 and 2 have been described. ${ }^{13}$ However, only three ceftriaxone-resistant infections have been reported in the United States, and each was associated with international travel. ${ }^{14}$ These 3 isolates were detected in 1995 in a national survey of more than 4000 isolates..$^{14}$ Ceftriaxone-resistant salmonella have been reported very rarely by national surveillance systems in the United Kingdom and Denmark, further demonstrating the low prevalence of ceftriaxone-resistant salmonella worldwide ${ }^{15}$ (and Threlfall EJ: personal communication).

Epidemiologic investigations have demonstrated that in the United States, the use of antimicrobial agents in livestock is the principal cause of the emergence and dissemination of resistance to antimicrobial agents in strains of nontyphoidal salmonella. ${ }^{16-18}$ However, few investigations have been successful in tracing antibiotic-resistant infections in humans to a source on a farm. We used molecular methods to establish a connection between a domestically acquired ceftriaxone-resistant salmonella infection in a child and related isolates from cattle.

\section{CASE REPORT}

In April 1998, a 12-year-old boy living in western Nebraska had acute abdominal pain with fever. The boy had been well with the exception of a sinus infection treated with amoxicillin-clavulanate. He had finished his 10-day course of treatment 4 days before the onset of abdominal pain. He began a prophylactic regimen of ampicillin-sulbactam and underwent an appendectomy. Histologic examination of the appendix showed acute mucosal inflammation but no involvement of the serosa or muscularis. Two days after surgery, treatment with ampicillin-sulbactam was discontinued and treatment with amoxicillin-clavulanate was begun. The following day the patient began to have diarrhea, and a stool

From the Nebraska Public Health Laboratory (P.D.F., P.C.I., S.H.H.) Omaha; the Departments of Internal Medicine (P.D.F., M.E.R.) and Pathology and Microbiology (P.D.F., P.C.I., S.H.H.), University of Nebraska Medical Center, Omaha; the Department of Health and Human Services, Lincoln, Nebr. (T.J.S.); the Foodborne and Diarrheal Diseases Branch, Division of Bacterial and Mycotic Diseases, National Center for Infectious Diseases, Centers for Disease Control and Prevention, Atlanta (E.F.D., E.R., F.J.A.); and Wyeth-Ayerst Research, Pearl River, N.Y. (P.A.B). Address reprint requests to Dr. Fey at the Departments of Internal Medicine and Pathology and Microbiology, University of Nebraska Medical Center, 985400 Nebraska Medical Center, Omaha, NE 68198-5400, or at pfey@ unmc.edu. 
culture yielded Salmonella enterica serotype typhimurium. The patient was discharged and had an uneventful recovery.

The isolate was analyzed at the Nebraska Public Health Laboratory and found to be resistant to ampicillin, chloramphenicol, tetracycline, sulfisoxazole, kanamycin, and streptomycin as well as to broad-spectrum cephalosporins (e.g., cephalothin) and expanded-spectrum cephalosporins (e.g., ceftriaxone, which is used in humans, and ceftiofur, which is used in animals), aztreonam, cefoxitin, gentamicin, and tobramycin. Further investigation was conducted by epidemiologists at the Nebraska Department of Health and Human Services and the Centers for Disease Control and Prevention (CDC). In March 1998, the patient's father had treated calves with a severe diarrheal disorder from his own herd and three other herds. Several of the calves had died. Stool specimens from ill cattle in each herd were analyzed at the University of Nebraska Panhandle Research and Extension Center and yielded S. enterica serotype typhimurium. During the two-week period before his illness, the boy had not accompanied his father on visits to other herds and had not traveled outside the United States.

Reports of the boy's illness prompted an investigation by public health officials. No additional ceftriaxone-resistant salmonella infections were reported in Nebraska or adjoining states.

\section{METHODS}

\section{Bacterial Strains and Antibiotic Susceptibility}

Five isolates of $S$. enterica serotype typhimurium were studied: the one from the boy and four from cattle (one from each herd associated with the outbreak of salmonellosis). The susceptibility of these isolates to antimicrobial agents was determined by the broth-microdilution or disk-diffusion method in accordance with the standards of the National Committee for Clinical Laboratory Standards ${ }^{19,20}$ and with the E test, according to the manufacturer's recommendations (AB Biodisk, Solona, Sweden). The double disk-diffusion assay was used to screen for the presence of extended-spectrum $\beta$-lactamases according to published methods. ${ }^{21}$ Isolates were serotyped and phage typed at the CDC with the use of standard methods. ${ }^{22}$

\section{Pulsed-Field Gel Electrophoresis and Plasmid Analysis}

Genomic DNA suitable for pulsed-field gel electrophoresis (PFGE) was prepared according to published methods and digested with the restriction endonuclease $\mathrm{X} b a \mathrm{I}$ (Roche, Indianapolis). ${ }^{23}$ Three salmonella isolates, including a strain of $S$. enterica serotype typhimurium known as definitive phage type 104 (DT104), from ill persons in Nebraska were used for comparison. Plasmids encoded by Escherichia coli V517,24 R1, ${ }^{25}$ and PDK9 (CDC strain collection) were used as size standards. Plasmid DNA from all strains studied was isolated with the use of either a kit (Qiagen midi-preps, Qiagen, Valencia, Calif.) or a modified alkaline lysis procedure. ${ }^{26}$

\section{Transconjugation Studies}

The isolate from the child, one of the cattle isolates (cattle isolate 1), and the DT104 isolate (which is resistant to ampicillin and susceptible to nalidixic acid) were transconjugated with $E$. coli $\mathrm{C} 600 \mathrm{~N},{ }^{27}$ which is resistant to nalidixic acid and susceptible to ampicillin, with the use of standard methods. ${ }^{28}$ DT104 was transconjugated with $\mathrm{C} 600 \mathrm{~N}$ to serve as a negative control. ${ }^{29}$

\section{Isoelectric Focusing}

Isoelectric focusing was performed according to the method of Mathew et al..$^{30}$ at $10^{\circ} \mathrm{C}$ (Multiphor apparatus, Pharmacia LKB, Uppsala, Sweden) with prepared polyacrylamide-gel plates $(\mathrm{pH}$ range, 3.5 to 9.5) (Pharmacia). TEM-1, TEM-2, Kl, SHV-1, and P99 $\beta$-lactamases were used as standards.

\section{Amplification, Sequencing, and Hybridization}

The polymerase-chain-reaction (PCR) primers that were used to identify the ampC gene of Citrobacter freundii and TEM-related sequences have been described previously. ${ }^{28,31}$ The sequence of both strands was analyzed. Southern hybridization was performed according to standard methods ${ }^{32}$ with DNA probes labeled with digoxigenin-11-deoxyuridine triphosphate (Roche).

\section{RESULTS}

\section{Susceptibility to Antibiotics, Serotype, and Phage Type of the Isolates}

The isolate from the child and the four isolates from cattle were serotyped at the CDC and found to be $S$. enterica serotype typhimurium variant Copenhagen. All five isolates had the same pattern of phage lysis, which did not match previously described type designations. Susceptibility testing revealed that the isolate from the child and cattle isolate 1 had an identical pattern, including resistance to ceftriaxone (minimal inhibitory concentration, $\geqslant 64 \mu \mathrm{g}$ of ceftriaxone per milliliter) and ceftiofur (minimal inhibitory concentration, $\geqslant 16 \mu \mathrm{g}$ of ceftiofur per milliliter). Although not resistant to ceftriaxone or ceftiofur, the other three isolates from cattle were resistant to five antimicrobial agents (ampicillin, tetracycline, kanamycin, streptomycin, and sulfisoxazole). Double diskdiffusion testing showed that the $\beta$-lactamase that conferred resistance to ceftriaxone and other expanded-spectrum cephalosporins was not inhibited by the $\beta$-lactamase inhibitor clavulanate and was therefore not phenotypically classified as an extended-spectrum $\beta$-lactamase (functional group 2be). ${ }^{13}$

\section{PFGE}

PFGE was used to determine the molecular relatedness of the isolate from the child and the four cattle isolates (Fig. 1). All five isolates had similar restriction-fragment patterns; however, they had a number of bands that differed from those of $S$. enterica serotype typhimurium DT104 and two non-DT104 control strains of $S$. enterica serotype typhimurium (REF42 and REF65) that were isolated in Nebraska. The isolate from the child and cattle isolate 1 , the two ceftriaxone-resistant isolates, were closely related except for differences in bands K and P (Fig. 1). Both ceftriaxone-resistant isolates also contained a $160-\mathrm{kb}$ band (band I) as well as a slightly larger band (band $\mathrm{H})$ that the ceftriaxone-susceptible isolates from cattle did not have. Cattle isolates 2 and 4 were identical, whereas cattle isolate 3 , although very similar to cattle isolates 2 and 4, differed with respect to band $\mathrm{K}$. Cattle isolate 1 was very similar to cattle isolates 2 and 4, except with respect to bands I and $H$. The isolate from the child appeared to have the same band $\mathrm{K}$ as cattle isolate 3 . The origin of these differences was subsequently determined.

\section{Transconjugation Experiments and Analysis of Plasmids}

To determine whether ceftriaxone and other antibiotic-resistance factors of the isolate from the child and cattle isolate 1 were mediated by plasmids, both strains were transconjugated with E. coli C600N. The 


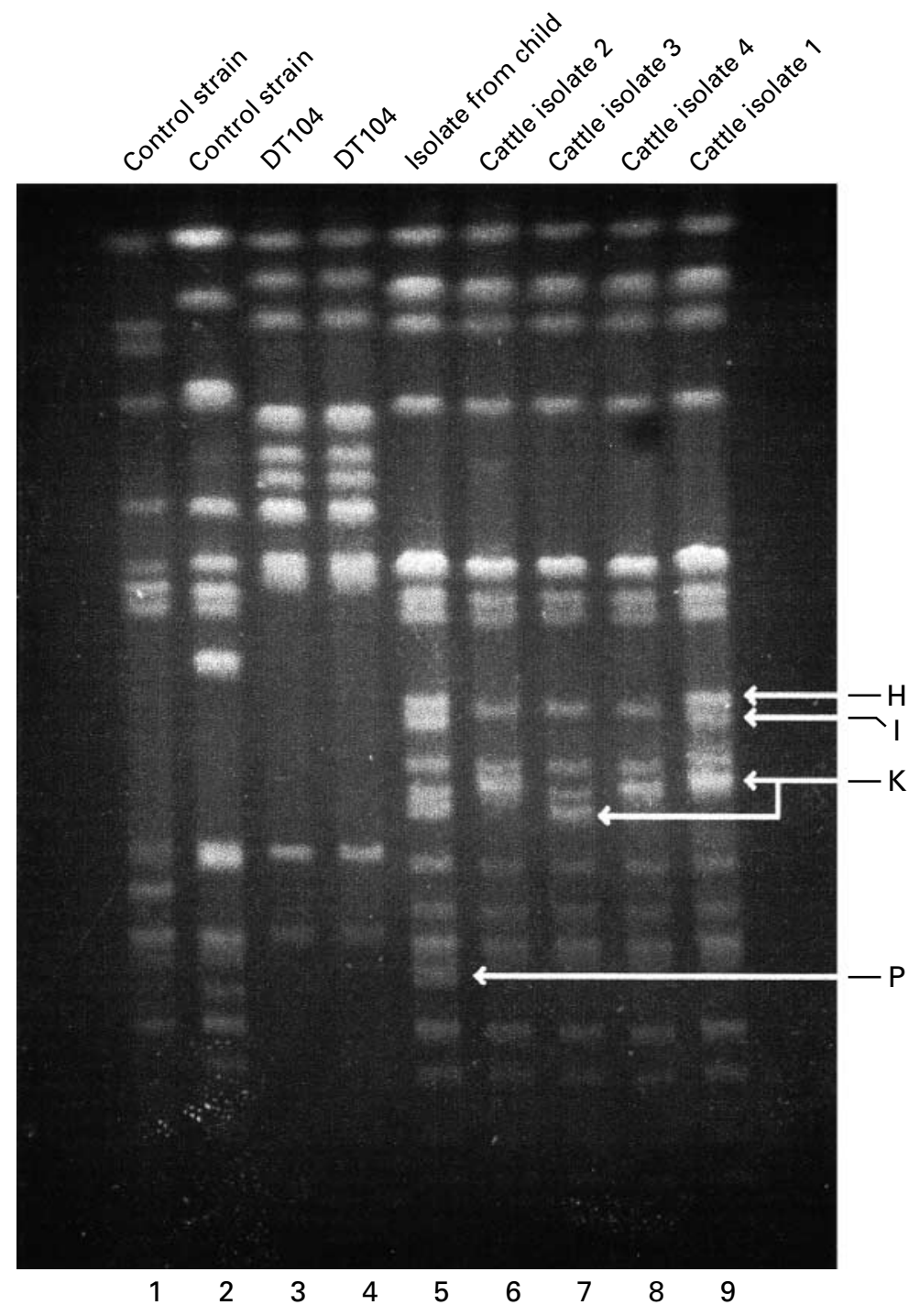

Figure 1. Results of Pulsed-Field Gel Electrophoresis of Isolates of Salmonella enterica Serotype Typhimurium from a 12-Year-Old Boy and Cattle.

Lanes 1 and 2 show control strains of $S$. enterica serotype typhimurium (REF42 and REF65, respectiveIy), lanes 3 and 4 S. enterica serotype typhimurium definitive phage type 104 (DT104), lane 5 the isolate from the child, lane 6 cattle isolate 2, lane 7 cattle isolate 3, lane 8 cattle isolate 4, and lane 9 cattle isolate 1. The isolate from the child includes a unique band, labeled $\mathrm{P}$. Bands $\mathrm{H}$ and I were found in both the isolate from the child and cattle isolate 1. There were additional differences among the isolates with respect to band $\mathrm{K}$. Bands $\mathrm{I}, \mathrm{K}$, and $\mathrm{P}$ were all found to be of plasmid origin.

transconjugants exhibited decreased susceptibility to all antimicrobial agents (including ceftriaxone, ceftiofur, and cefoxitin) to which the isolate from the child and cattle isolate 1 were resistant, except kanamycin (data not shown). The results of PFGE used to confirm the E. coli $\mathrm{C} 600 \mathrm{~N}$ lineage showed an additional $X b a \mathrm{I}$ band in each ceftriaxone-resistant transconjugant. This new band was the same size as band I in both ceftriaxone-resistant salmonella isolates, suggesting that this band carried the genetic material mediating resistance to ceftriaxone.
The isolates from the child and the cattle were analyzed for plasmids. The two ceftriaxone-resistant isolates (lanes 1 and 2 in Fig. 2A) both had plasmid bands of $160 \mathrm{~kb}$. The isolate from the child contained two additional plasmids, one of $55 \mathrm{~kb}$ and one of $125 \mathrm{~kb}$. The band of $125 \mathrm{~kb}$ was also present in cattle isolates 2 and 3 (lanes 3 and 4, respectively, in Fig. 2A) and cattle isolate 4 (data not shown). Plasmid bands of $140 \mathrm{~kb}$ were seen in cattle isolates 1 and 2 (Fig. 2A). The plasmid profiles of cattle isolates 2 and 4 were indistinguishable (data not shown). 


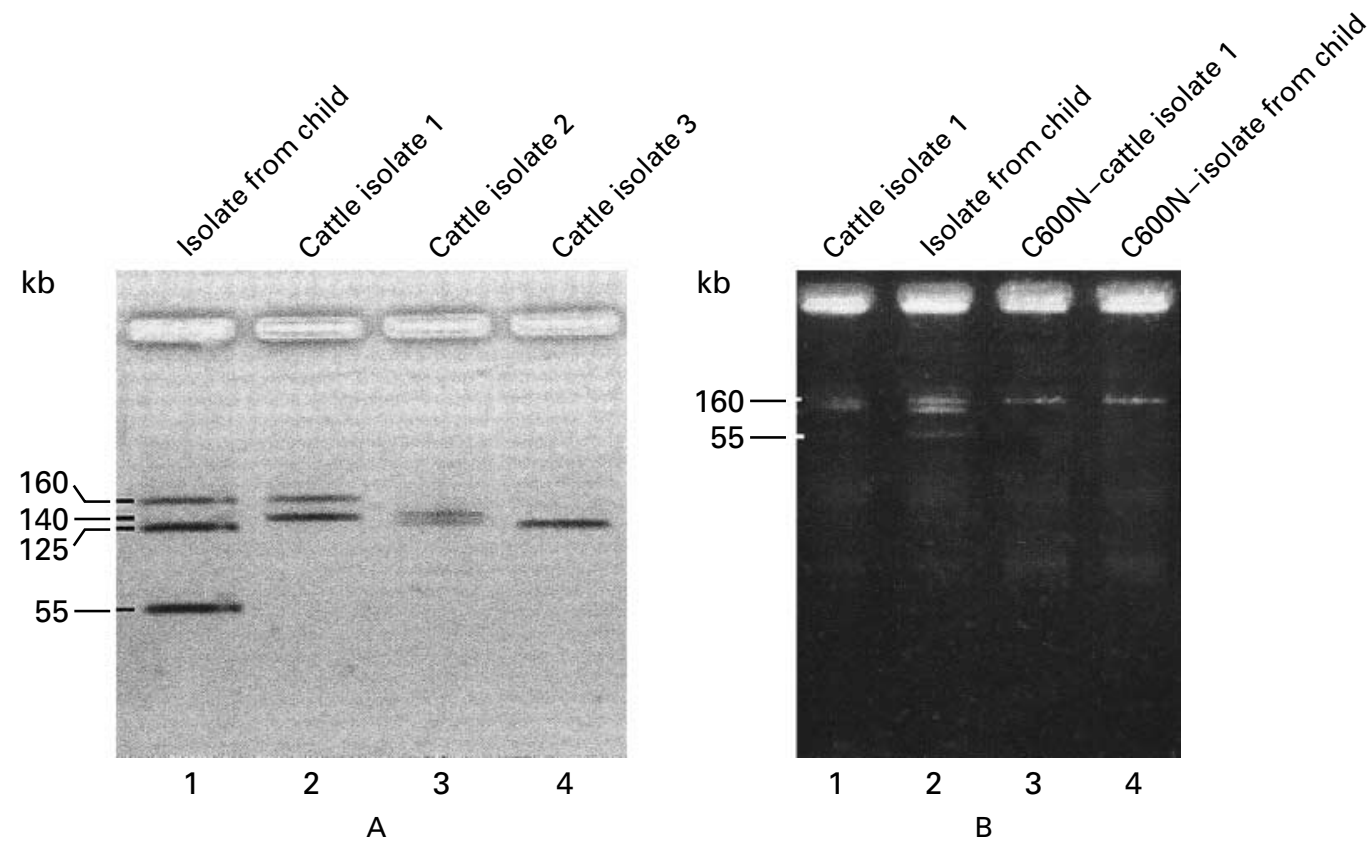

Figure 2. Plasmid Analysis of Isolates of Salmonella enterica Serotype Typhimurium and of Transconjugants.

The results for cattle isolate 4 are not shown. Panel A shows the 160-kb plasmid that was found in the isolate from the child (lane 1) and cattle isolate 1 (lane 2); the 140-kb plasmid that was found in cattle isolates 1, 2 (lane 3), and 4; the 125-kb plasmid that was found in the isolate from the child and cattle isolates 2, 3 (lane 4), and 4; and the 55-kb plasmid that was found only in the isolate from the child. Panel B shows the plasmids found in ceftriaxone-resistant transconjugants of Escherichia coli $\mathrm{C} 600 \mathrm{~N}$ and S. enterica serotype typhimurium. The 160-kb conjugative plasmid found only in the ceftriaxone-resistant cattle isolate 1 (lane 1) and the isolate from the child (lane 2) was transferred by transconjugation of these isolates with E. coli C600N (lanes 3 and 4, respectively). The 55-kb plasmid in the isolate from the child was not transferred.

The plasmid profiles of the salmonella isolates and the E. coli $6000 \mathrm{~N}$ transconjugants resulting from transconjugation with the isolate from the child and cattle isolate 1 were compared. The ceftriaxone-resistant transconjugants both contained the band of 160 $\mathrm{kb}$ that was found in cattle isolate $\mathrm{l}$ and the isolate from the child (Fig. 2B), but not the bands of $55 \mathrm{~kb}$ and $125 \mathrm{~kb}$ that were found in the isolate from the child or the $140-\mathrm{kb}$ band that was found in cattle isolate 1 .

\section{$\beta$-Lactamase Analysis}

Isoelectric focusing was performed to characterize the $\beta$-lactamases present in the five salmonella isolates and the ceftriaxone-resistant transconjugants. Cattle isolates 2,3 , and 4 all expressed one $\beta$-lactamase with an isoelectric point of 5.4. This finding, in conjunction with their antibiotic-resistance profile, suggested that these isolates produced a TEM-1like $\beta$-lactamase. The isolate from the child and cattle isolate 1 produced not only the TEM-1-like $\beta$-lactamase but also one with an isoelectric point of at least 9.0, suggestive of an AmpC-like enzyme. Moreover, all four ceftriaxone-resistant transconjugants contained the AmpC-like $\beta$-lactamase (isoelectric point, $\geqslant 9.0$ ), further suggesting that this $\beta$-lactamase was responsible for the ceftriaxone resistance and that it was encoded on the conjugative plasmid of approximately $160 \mathrm{~kb}$. The TEM-1-like $\beta$-lactamase was not present in the transconjugants.

Specific primers for the ampC gene of C. freundii were used to characterize the AmpC-like $\beta$-lactamase found in the isolate from the child, cattle isolate 1 , and their transconjugants. This analysis yielded a PCR product of the expected size (631 bp) from the isolate from the child, cattle isolate 1 , and their transconjugants. Cattle isolates 2, 3, and 4 were negative on PCR testing for the 631-bp amplicon. These findings indicated that a $\beta$-lactamase (isoelectric point, $\geqslant 9.0$ ) closely related to the ampC gene of $C$. freundii was responsible for the ceftriaxone resistance of these isolates.

To characterize the $\beta$-lactamase with an isoelectric point of 5.4 that was present in all the salmonella isolates, primers specific for the TEM family of $\beta$-lactamases were used. All isolates were positive, but the transconjugants were negative. This finding demonstrated that the TEM-1-like $\beta$-lactamase was not encoded on the same plasmid as the AmpC-like $\beta$-lactamase. 
To prove that the AmpC-like $\beta$-lactamase was encoded on the $160-\mathrm{kb}$ plasmid that was found only in the isolate of the child, cattle isolate 1 , and their transconjugants, C. freundii ampC-like PCR products were labeled and used as probes. Southern blot analysis of a PFGE gel (Fig. 3) demonstrated that the AmpC-like $\beta$-lactamase probe hybridized to band I, which was found only in the ceftriaxone-resistant isolate from the child, cattle isolate 1 , and their transconjugants. Since transconjugation studies had shown that the AmpC-like $\beta$-lactamase was derived from a plasmid, we concluded that the additional band I was the unique $160-\mathrm{kb}$ plasmid that was found in the ceftriaxone-resistant isolates.

Southern blot analysis demonstrated that the TEM-1 $\beta$-lactamase was encoded on the plasmids in all clinical isolates and not on the chromosome (data not shown). This analysis demonstrated that TEM-1 was encoded on the $125-\mathrm{kb}$ plasmid in the isolate from the child and cattle isolate 3 and on the $140-\mathrm{kb}$ plasmid in cattle isolates 1,2 , and 4 , raising the possibility that band $\mathrm{K}$ was derived from a plasmid. To answer this question, we hybridized DNA, which had been separated by PFGE, with a TEM-1 probe (Fig. 4 ). These results demonstrated that band $\mathrm{K}$ was derived from a plasmid and represented the $125-\mathrm{kb}$ plasmid found in both the isolate from the child and cattle isolate 3 and the $140-\mathrm{kb}$ plasmid found in catthe isolates 1,2 , and 4 .

To determine whether the $55-\mathrm{kb}$ plasmid that was found in the isolate from the child represented band $P$ identified on PFGE analysis, plasmid DNA and chromosomal DNA digested with $X b a \mathrm{I}$ were electrophoresed on the same gel. The analysis showed that band $\mathrm{P}$ was the same size as the plasmid.

\section{DNA Sequencing}

The AmpC-like $\beta$-lactamase from the ceftriaxoneresistant transconjugant of $E$. coli $\mathrm{C} 600 \mathrm{~N}$ and the isolate from the child was completely sequenced and found to be 100 percent homologous to the plasmidic cephamycinase CMY-2. ${ }^{33}$

\section{DISCUSSION}

On the basis of reports sent to the CDC, we believe that this case represents the first documented domestically acquired ceftriaxone-resistant salmonella infection in the United States. Although the means of transmission is not known, the child apparently acquired the illness from cattle. Several lines of evidence, in addition to the epidemiologic findings, support the hypothesis that the child's gastrointestinal infection was acquired from cattle on his family's ranch or nearby ranches that had had outbreaks of salmonellosis among cattle. First, the isolate from the child and all the cattle isolates were $S$. enterica serotype typhimurium variant Copenhagen and had the same distinct pattern of phage lysis. Second, the iso-

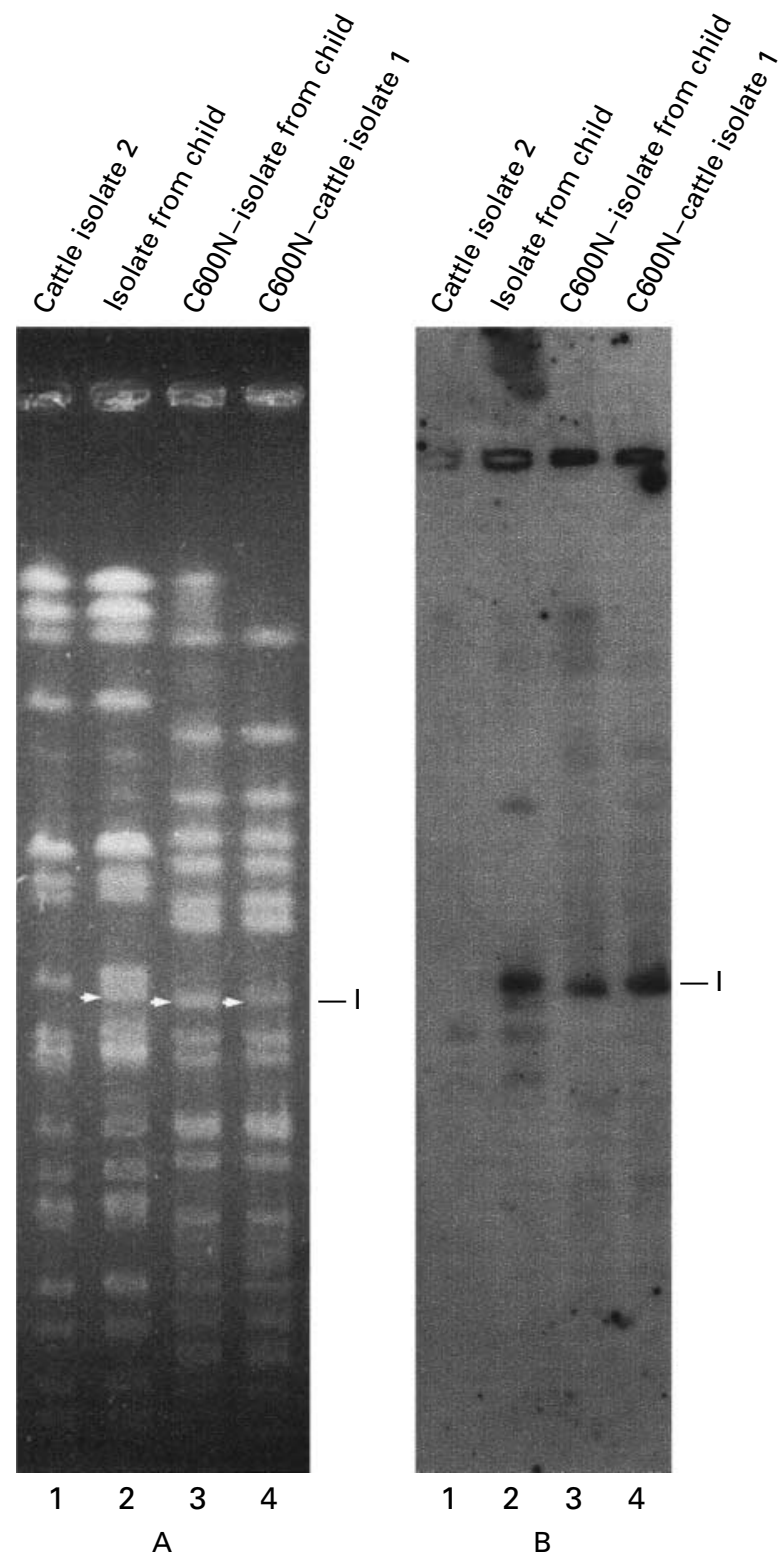

Figure 3. Results of Pulsed-Field Gel Electrophoresis of Isolates of Salmonella enterica Serotype Typhimurium from a 12-YearOld Boy and Cattle and of Transconjugants.

In each panel, lane 1 shows cattle isolate 2 , lane 2 the isolate from the child, and lanes 3 and 4 ceftriaxone-resistant transconjugant of Escherichia coli $\mathrm{C} 600 \mathrm{~N}$ with the isolate from the child and cattle isolate 1, respectively. In Panel A, band I was found only in the ceftriaxone-resistant isolates and their ceftriaxoneresistant transconjugants. In Panel B, Southern blot analysis with $c m y-2$ PCR product as the probe indicates that band $I$ is of plasmid origin and corresponds to the $160-\mathrm{kb}$ plasmid shown in Figure 2. There is no hybridization in ceftriaxone-susceptible cattle isolate 2 . 

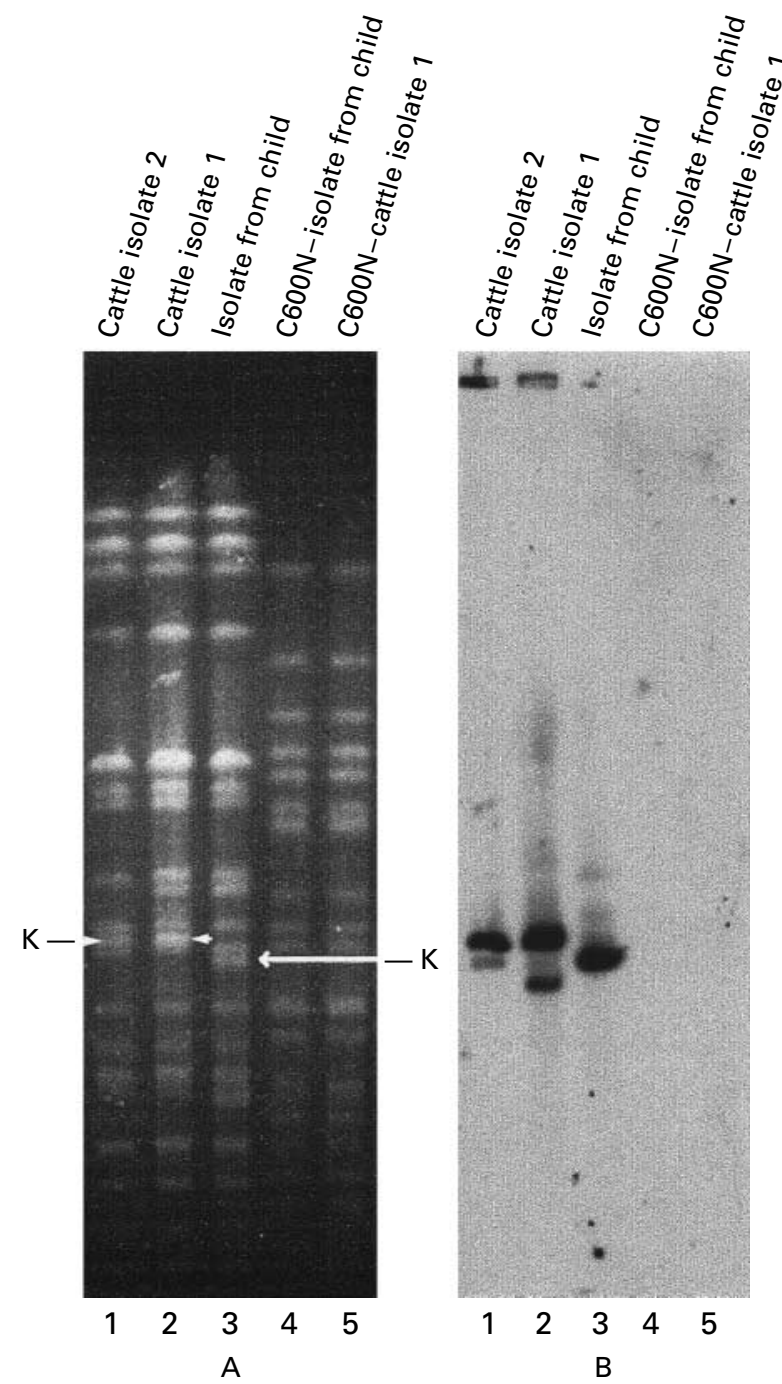

Figure 4. Results of Pulsed-Field Gel Electrophoresis of Isolates of Salmonella enterica Serotype Typhimurium from a 12-YearOld Boy and Cattle and of Transconjugants.

In each panel, lane 1 shows cattle isolate 2 , lane 2 cattle isolate 1 , lane 3 isolate from the child, lane 4 the ceftriaxone-resistant transconjugant of Escherichia coli $\mathrm{C} 600 \mathrm{~N}$ and the isolate from the child, and lane 5 the ceftriaxone-resistant transconjugant of E. coli $\mathrm{C} 600 \mathrm{~N}$ and cattle isolate 1. Panel A shows band $\mathrm{K}$, and Panel $B$ shows the results of Southern blot hybridization with a 952-bp TEM-1 PCR product amplified from the isolate from the child. The results indicate that band $\mathrm{K}$ is of plasmid origin and encodes TEM- $1 \beta$-lactamase. The additional bands in lanes 1 and 2 of Panel B may indicate nicked or supercoiled forms of the plasmids that encode TEM-1. There was no hybridization of the TEM-1 probe in the ceftriaxone-resistant transconjugants (lanes 4 and 5).

late from the child and one of the cattle isolates (cattle isolate 1) had the same, extremely rare pattern of resistance to antibiotics. Finally, the presence of plasmid DNA could account for almost all the differences in bands among the isolates that were found on PFGE. These differences between cattle isolate 1 and the iso- late from the child were in two bands ( $\mathrm{K}$ and $\mathrm{P}$ ) subsequently shown to be of plasmid origin. Therefore, the isolate from the child and cattle isolate $\mathrm{l}$ can be considered to be the same strain. One additional band (I), unique to the ceftriaxone-resistant isolates, was also shown to be of plasmid origin and encoded a CMY-2 $\beta$-lactamase as well as other antibiotic-resistance genes. The only genomic differences among the isolate from the child, cattle isolate 1 , and the ceftriaxone-susceptible cattle isolates lay in the larger size of band $\mathrm{H}$ in both cattle isolate $\mathrm{l}$ and the isolate from the child. According to the criteria of Tenover et al. for analysis of banding patterns on PFGE, all the isolates were highly related. ${ }^{34}$

Although antimicrobial therapy is not essential for the treatment of most salmonella infections, such therapy may be lifesaving in persons with invasive disease. Expanded-spectrum cephalosporins, especially ceftriaxone, are frequently used empirically to treat salmonella infections in children. The identification of a domestically acquired CMY-2-mediated ceftriaxone-resistant salmonella infection and its apparent circulation in cattle suggest that such infections could become more common in the United States, especially since the resistance to ceftriaxone is mediated by a plasmid. There are few alternative antimicrobial agents for the empirical treatment of salmonella infections in children, since fluoroquinolones have not been approved for use in children.

Our findings add to the accumulating body of evidence suggesting that the use of antimicrobial agents in livestock is the dominant source of resistance to these agents in salmonella. Previous studies have shown that salmonella isolates from both humans and animals share antibiotic-resistance plasmids. ${ }^{35} \mathrm{Al}-$ though no information was available regarding the use of antimicrobial agents among the four infected herds on the patient's ranch and neighboring ranches, the results of PFGE suggest that the ceftriaxone-resistant strain of $S$. enterica serotype typhimurium variant Copenhagen that infected the child was present in at least one herd. In addition, the ceftriaxone-resistant isolate from cattle (cattle isolate 1 ) was closely related to other, possibly endemic, ceftriaxone-susceptible isolates of $S$. enterica serotype typhimurium variant Copenhagen that were obtained during the same outbreak of salmonellosis (cattle isolates 2, 3, and 4).

It is probable that the use of antimicrobial agents in cattle led to the selection of the ceftriaxone-resistant strain that was subsequently transmitted to the child. Although we were unable to establish its use in these herds, an expanded-spectrum cephalosporin (ceftiofur) is approved for use and is widely used in domestic animals, including cattle. Other factors besides cephalosporin use (e.g., the use of other antibiotics or unknown environmental factors) could have selected for and maintained this plasmid within the bacterial population in the involved herds. Although 
the means of transmission of the ceftriaxone-resistant salmonella from the cattle to the child is not known, it is unlikely that the child acquired the infection through food. Therefore, even if salmonella is eliminated from food, the circulation of highly resistant strains in livestock constitutes a potential public health threat, especially to farmers, ranchers, and animal handlers.

The inoculum of salmonella necessary to cause illness in this child may have been lowered by the prior treatment with amoxicillin-clavulanate and ampicillin-sulbactam. The use of antibiotics during or before exposure has frequently been shown to predispose persons to salmonella infections. ${ }^{16,36}$ Our findings illustrate the need to use antimicrobial agents prudently both in domestic animals and in humans. The implementation of appropriate safeguards, including restricting the use of certain antimicrobial agents in livestock, may slow the evolution of antimicrobial resistance in salmonella and prevent the transmission of resistant strains of salmonella from livestock to humans.

Our findings demonstrate the ability of nationwide monitoring programs to detect new antibiotic-resistant strains of bacteria before they become widely disseminated. Continued surveillance for antibiotic-resistant salmonella in livestock and humans is necessary, particularly to monitor the incidence of ceftriaxoneresistant strains. In this respect, testing for CMY-2mediated resistance will be useful to identify the spread of related strains or plasmids in the United States.

Supported in part by a grant from the University of Nebraska Medical Center.

We are indebted to Dr. Jeff Gray (Veterinary Diagnostic Center, University of Nebraska, Lincoln) and Dr. Dale Grotelueschen (Panhandle Research and Extension Center, University of Nebraska, Lincoln) for their active collaboration.

\section{REFERENCES}

1. Mead PS, Slutsker L, Dietz V, et al. Food-related illness and death in the United States. Emerg Infect Dis 1999;5:607-25.

2. Marano N, Stamey K, Barrett TJ, Tollefson L, Angulo FJ. Emerging resistance among U.S. Salmonella strains to quinolones and extended-spectrum cephalosporins, 1996-1998. In: Abstracts of the 99th General Meeting of the American Society for Microbiology, Washington, D.C., May 30June 3, 1999:163. abstract.

3. Barnaud G, Arlet G, Verdet C, Gaillot O, Lagrange PH, Philippon A. Salmonella enteritidis: AmpC plasmid-mediated inducible $\beta$-lactamase (DHA-1) with an ampR gene from Morganella morganii. Antimicrob Agents Chemother 1998;42:2352-8.

4. Koeck JL, Arlet G, Philippon A, et al. A plasmid-mediated CMY-2 $\beta$-lactamase from an Algerian clinical isolate of Salmonella senftenberg. FEMS Microbiol Lett 1997; 152:255-60.

5. Archambaud M, Gerbaud G, Labau E, Marty N, Courvalin P. Possible in-vivo transfer of $\beta$-lactamase TEM-3 from Klebsiella pneumoniae to Salmonella kedougou. J Antimicrob Chemother 1991;27:427-36.

6. Poupart M-C, Chanal C, Sirot D, Labia R, Sirot J. Identification of CTX-2, a novel cefotaximase from a Salmonella mbandaka isolate. Antimicrob Agents Chemother 1991;35:1498-500.

7. Bauernfeind A, Casellas JM, Goldberg M, et al. A new plasmidic cefotaximase from patients infected with Salmonella typhimurium. Infection 1992;20:158-63.

8. Vahaboglu H, Hall LMC, Mulazimoglu L, Dodanli S, Yildirim I, Liv ermore DM. Resistance to extended-spectrum cephalosporins, caused by
PER-1 $\beta$-lactamase, in Salmonella typhimurium from Istanbul, Turkey

J Med Microbiol 1995;43:294-9.

9. Rossi A, Lopardo H, Woloj M, et al. Non-typhoid Salmonella spp. re sistant to cefotaxime. J Antimicrob Chemother 1995;36:697-702.

10. Maiorini E, Lopez EL, Morrow AL, et al. Multiply resistant nontyphoidal Salmonella gastroenteritis in children. Pediatr Infect Dis J 1993;12:139-45. 11. Hammami A, Arlet G, Ben Redjeb S, et al. Nosocomial outbreak of acute gastroenteritis in a neonatal intensive care unit in Tunisia caused by multiply drug resistant Salmonella wien producing SHV-2 $\beta$-lactamase. Eur J Clin Microbiol Infect Dis 1991;10:641-6.

12. Bradford PA, Yang Y, Sahm D, Grope I, Gardovska D, Storch G. CTXM-5, a novel cefotaxime-hydrolyzing $\beta$-lactamase from an outbreak of Salmonella typhimurium in Latvia. Antimicrob Agents Chemother 1998;42: 1980-4

13. Bush K, Jacoby GA, Medeiros AA. A functional classification scheme for $\beta$-lactamases and its correlation with molecular structure. Antimicrob Agents Chemother 1995;39:1211-33.

14. Herikstad H, Haves PS, Hogan J, Floyd P, Snyder L, Angulo FJ. Ceftriaxone-resistant Salmonella in the United States. Pediatr Infect Dis J 1997;9:904-5.

15. Aarestrup FM, Bager F, Jensen NE, Madsen M, Meyling A, Wegener HC. Resistance to antimicrobial agents used for animal therapy in pathogenic-, zoonotic- and indicator bacteria isolated from different food animals in Denmark: a baseline study for the Danish Integrated Antimicrobial Resistance Monitoring Programme (DANMAP). APMIS 1998;106:745-70.

16. Cohen ML, Tauxe RV. Drug-resistant Salmonella in the United States: an epidemiological perspective. Science 1986;234:964-9.

17. van den Bogaard AE, Stobberingh EE. Antibiotic usage in animals: im pact on bacterial resistance and public health. Drugs 1999;58:589-607.

18. Mølbak K, Baggesen DL, Aarestrup FM, et al. An outbreak of multidrug-resistant, quinolone-resistant Salmonella enterica serotype typhimurium DT104. N Engl J Med 1999;19:1420-5.

19. Methods for dilution antimicrobial susceptibility tests for bacteria that grow aerobically. Approved standard M7-A4. Wayne, Pa.: National Committee for Clinical Laboratory Standards, 1997.

20. Performance standards for antimicrobial disk susceptibility tests. Approved standard M2-A6. Wayne, Pa.: National Committee for Clinical Laboratory Standards, 1997.

21. Vercauteren $E$, Descheemaeker $P$, Ieven $M$, Sanders CC, Goossens $H$. Comparison of screening methods for detection of extended-spectrum $\beta$-lactamases and their prevalence among blood isolates of Escherichia coli and Klebsiella spp. in a Belgian teaching hospital. J Clin Microbiol 1997;35:2191-7.

22. Anderson ES, Ward LR, Saxe MJ, de Sa JD. Bacteriophage-typing designations of Salmonella typhimurium. J Hyg (Lond) 1977;78:297-300.

23. Gautom RK. Rapid pulsed-field gel electrophoresis protocol for typing of Escherichia coli $\mathrm{O} 157: \mathrm{H} 7$ and other gram-negative organisms in 1 day. J Clin Microbiol 1997;35:2977-80.

24. Mayer LW. Use of plasmid profiles in epidemiologic surveillance of disease outbreaks and tracing the transmission of antibiotic resistance. Clin Microbiol Rev 1988;1:228-43.

25. Rochelle PA, Fry JC, Day MJ, Bale MJ. An accurate method for estimating sizes of small and large plasmids and DNA fragments by gel electrophoresis. J Gen Microbiol 1986;132:53-9.

26. Sinnett D, Richer C, Baccichet A. Isolation of stable bacterial artificial chromosome DNA using a modified alkaline lysis method. Biotechniques $1998 ; 24: 752-4$

27. Bachmann BJ. Derivations and genotypes of some mutant derivatives of Escherichia coli K-12. In: Neidhardt FC, ed. Escherichia coli and Salmonella typhimurium: cellular and molecular biology. Vol. 2. Washington, D.C.: American Society for Microbiology, 1987:1197-219.

28. Pitout JDD, Thomson KS, Hanson ND, Ehrhardt AF, Moland ES, Sanders CC. $\beta$-Lactamases responsible for resistance to expanded-spectrum cephalosporins in Klebsiella pneumoniae, Escherichia coli, and Proteus mirabilis isolates recovered in South Africa. Antimicrob Agents Chemother 1998;42:1350-4.

29. Briggs CE, Fratamico PM. Molecular characterization of an antibiotic resistance gene cluster of Salmonella typhimurium DT104. Antimicrob Agents Chemother 1999;43:846-9.

30. Mathew A, Harris AM, Marshall MJ, Ross GW. The use of analytical isoelectric focusing for detection and identification of $\beta$-lactamases. J Gen Microbiol 1975;88:169-78

31. M'Zali FH, Heritage J, Gascoyne-Binzi DM, Denton M, Todd NJ, Hawkey PM. Transcontinental importation into the UK of Escherichia coli expressing a plasmid-mediated AmpC-type $\beta$-lactamase exposed during an outbreak of SHV-5 extended-spectrum $\beta$-lactamase in a Leeds hospital. J Antimicrob Chemother 1997;40:823-31.

32. Sambrook J, Fritsch EF, Maniatis T. Molecular cloning: a laboratory manual. 2nd ed. Cold Spring Harbor, N.Y.: Cold Spring Harbor Laboratory Press, 1989.

33. Bauernfeind A, Stemplinger I, Jungwirth R, Giamarellou H. Charac- 
terization of the plasmidic $\beta$-lactamase CMY-2, which is responsible for cephamycin resistance. Antimicrob Agents Chemother 1996;40:221 4.

34. Tenover FC, Arbeit RD, Goering RV, et al. Interpreting chromosoma DNA restriction patterns produced by pulsed-field gel electrophoresis: criteria for bacterial strain typing. J Clin Microbiol 1995;33:2233-9.
35. O'Brien TF, Hopkins JD, Gilleece E, et al. Molecular epidemiology of antibiotic resistance in salmonella from animals and human beings in the United States. N Engl J Med 1982;307:1-6.

36. Pavia AT, Shipman LD, Wells JG, et al. Epidemiologic evidence that prior antimicrobial exposure decreases resistance to infection by antimicrobial-sensitive Salmonella. J Infect Dis 1990;161:255-60 